\title{
IMIII Case Management may Reduce Emergency Department Frequent use in a Universal Health Coverage System: a Randomized Controlled Trial
}

\author{
Patrick Bodenmann, MD, MSc' ', Venetia-Sofia Velonaki, PhD², Judith L. Griffin, $M D^{7}$, \\ Stéphanie Baggio, $P h D^{3}$, Katia lglesias, $P h D^{4,5}$, Karine Moschetti, PhD ${ }^{5,6,7}$, Ornella Ruggeri, Psych $D^{8}$, \\ Bernard Burnand, MD MPH ${ }^{5}$, Jean-Blaise Wasserfallen, MD MPP', Francis Vu, MD', \\ Joelle Schupbach, $R N^{7}$, Olivier Hugli, MD MPH ${ }^{9}$, and Jean-Bernard Daeppen, $\mathrm{MD}^{10}$
}

\begin{abstract}
'Vulnerable Populations Center, Department of Ambulatory Care and Community Medicine, University of Lausanne, Lausanne, Switzerland; ${ }^{2}$ Institute of Higher Education and Research in Healthcare, Department of Community Medicine and Public Health, Lausanne University Hospital and University of Lausanne, Lausanne, Switzerland; ${ }^{3}$ Life Course and Social Inequality Research Center, Faculty of Social and Political Sciences, University of Lausanne, Lausanne, Switzerland; ${ }^{4}$ Center for the Understanding of Social Processes, University of Neuchâtel, Neuchâtel, Switzerland; ${ }^{5}$ Institute of social and preventive medicine, Lausanne University Hospital, Lausanne, Switzerland; ${ }^{6}$ Technology Assessment Unit, Lausanne University Hospital, Lausanne, Switzerland; ${ }^{7}$ IEMS - Plateforme interfacultaire en économie et management de la santé, University of Lausanne, Lausanne, Switzerland; ${ }^{8}$ Department of Community Medicine and Public Health, Lausanne University Hospital, Lausanne, Switzerland; ${ }^{9}$ Emergency Department, Lausanne University Hospital, Lausanne, Switzerland; ${ }^{10}$ Alcohol Treatment Center, Lausanne University Hospital, Lausanne, Switzerland.
\end{abstract}

BACKGROUND: Frequent emergency department (ED) users account for a disproportionately high number of ED visits. Studies on case management (CM) interventions to reduce frequent $\mathrm{ED}$ use have shown mixed results, and few studies have been conducted within a universal health coverage system.

OBJECTIVE: To determine whether a CM intervention-compared to standard emergency care-reduces ED attendance.

DESIGN: Randomized controlled trial.

PARTICIPANTS: Two hundred fifty frequent ED users (5 or more visits in the prior 12 months) who visited a public urban ED at the Lausanne University Hospital between May 2012 and July 2013 were allocated to either an intervention $(n=125)$ or control $(n=125)$ group, and monitored for 12 months.

INTERVENTIONS: An individualized CM intervention consisting of concrete assistance in obtaining income entitlements, referral to primary or specialty medical care, access to mental health care or substance abuse treatment, and counseling on at-risk behaviors and health care utilization (in addition to standard care) at baseline and 1,3 , and 5 months.

MAIN MEASURES: We used a generalized linear model for count data (negative binomial distribution) to compare the number of ED visits during the 12-month follow-up between $\mathrm{CM}$ and usual care, from an intention-to-treat perspective.

Trial registration ClinicalTrials.gov Identifier: NCTO1934322

Electronic supplementary material The online version of this article (doi:10.1007/s11606-016-3789-9) contains supplementary material, which is available to authorized users.

Received January 14, 2016

Revised May 4, 2016

Accepted June 21, 2016

Published online July 11, 2016
KEY RESULTS: At 12 months, there were $2.71( \pm 0.23)$ ED visits in the intervention group versus $3.35( \pm 0.32)$ visits among controls (ratio $=0.81,95 \% \mathrm{CI}=0.63 ; 1.02$ ). In the multivariate model, the effect of the $\mathrm{CM}$ intervention on the number of ED visits approached statistical significance $(b=-0.219, p=0.075)$. The presence of poor social determinants of health was a significant predictor of ED use in the multivariate model $(b=0.280, p=0.048)$. CONCLUSIONS: CM may reduce ED use by frequent users through an improved orientation to the health care system. Poor social determinants of health significantly increase use of the ED by frequent users.

KEY WORDS: case management; vulnerable populations; utilization; clinical trials.

$\mathrm{J}$ Gen Intern Med 32(5):508-15

DOI: $10.1007 / \mathrm{s} 11606-016-3789-9$

๑) Society of General Internal Medicine 2016

\section{INTRODUCTION}

Frequent emergency department (ED) users account for 3 to $8 \%$ of all patients and 12 to $28 \%$ of all ED visits, ${ }^{1,2}$ contributing to overcrowding. ${ }^{3}$ Common reasons for such frequent use include pain, chronic physical

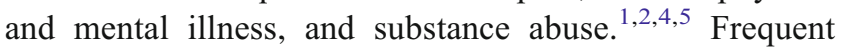
ED users are mainly men, are between 40 and 50 years of age, are sicker and have higher rates of mortality than occasional ED users. ${ }^{1,2,6}$ As such, they merit focused attention, and research on interventions to meet their needs is needed. ${ }^{6}$

Case management $(\mathrm{CM})$ is an intervention designed to assist frequent $\mathrm{ED}$ users in reducing their ED utilization. ${ }^{7,8} \mathrm{CM}$ aims to meet patients' individual needs and to optimize resource allocation for the frequent user and payer. ${ }^{9,10}$ To our knowledge, only 
three randomized controlled trials (RCTs) have examined the impact of CM on ED use. ${ }^{11-13}$ Two RCTs ${ }^{12,13}$ found that CM reduced the number of $\mathrm{ED}$ visits among frequent users, while the third ${ }^{11}$ found no significant impact. A randomized informationsharing intervention did not result in a significant reduction in ED use. ${ }^{14}$ Health care system characteristics and insurance coverage are factors that influence ED use, ${ }^{15}$ and may explain discrepancies among these studies.

According to a study conducted in Switzerland, ${ }^{16}$ frequent ED users accounted for $4.4 \%$ of all ED patients and $12.1 \%$ of all ED visits at the Lausanne University Hospital in 2008 2009. Like the majority of developed countries $(91 \%$ of OECD member nations), ${ }^{17}$ Switzerland has universal health coverage, established in 1994. The system relies on mandatory individual health insurance, with government subsidies available, and less than $1 \%$ of the population is uninsured. ${ }^{18}$

In response to calls for a unified definition of frequent ED use and primary care-based interventions ${ }^{4}$, this RCT examined whether an interdisciplinary $\mathrm{CM}$ intervention, compared to standard emergency care, would reduce ED utilization among frequent users through an improved orientation to primary care and other community-based services within a universal health coverage system.

\section{METHODS}

\section{Study design, setting and participants}

Details on the study design and protocol were published in our previous work. ${ }^{19}$ Briefly, we conducted an RCT with a parallel design to compare $\mathrm{CM}$ with standard care among frequent ED users of the Lausanne University Hospital (Switzerland) ED between May 2012 and July 2013. The Lausanne University Hospital is one of five EDs in the canton (state) of Vaud, and serves 770,000 people, with over 35,000 ED visits annually. ${ }^{20}$ We defined frequent ED users as those who made five or more ED visits during the prior 12 months, including the index visit, using a validated definition. ${ }^{1}$ Participants were randomized to the $\mathrm{CM}$ intervention or control group, and were monitored over 12 months. The primary outcome was the number of $\mathrm{ED}$ visits made by participants over the 12 month follow-up.

Participants were required to be at least 18 years of age and able to communicate in any language spoken by the team (French, English, Spanish, German, or Italian) or through a professional interpreter. Patients were excluded from the study if they 1) were unable to give informed consent, 2) planned to stay in Switzerland less than 18 months, 3) were not expected to survive at least 18 months (based on clinical judgment of research team, with systematic, proactive input from clinical providers, e.g. cardiologists or oncologists), 4) were awaiting incarceration or currently incarcerated, 5) had already received CM services, or 6) had a family member already enrolled in the study.

The trial was approved by the Human Research Ethics Committee of the Canton of Vaud, Switzerland (no. 32/12), and all participants provided written informed consent. The trial was funded by the Swiss National Science Foundation (no. 32003B_135762) and was registered on ClinicalTrials.gov (NCT01934322).

\section{Sample Size}

Based on results from a systematic review of the literature, ${ }^{7}$ the sample size estimate was calculated to detect an average difference of two ED visits annually between the two groups (i.e. four fewer intervention group visits compared to two fewer control group visits, with an anticipated standard deviation of four in both groups). Eighty-five participants were needed in both groups using a significance level of 0.05 and power of 0.9. We anticipated a dropout rate of $30 \%$, based on the increased mortality rate of frequent ED users, ${ }^{21}$ past research ${ }^{19,22}$ and clinical experience of the CM team (serving populations including forced migrants and homeless persons), due to the instability in this population. Thus, we aimed to enroll 250 frequent ED users (125 in each group).

\section{Recruitment, randomization, allocation and blinding}

We identified frequent users using a continuous automated detection system linked with ED patient tracking software. Study staff provided frequent users with oral and written information about the study. Due to pragmatic constraints (e.g. after hours; simultaneous participants), the single research nurse was not able to approach all eligible frequent users. If a frequent user left the ED prior to contact with the study staff, a team member attempted to reach him/her by telephone up to three times within 24-72 hours, to explain the study and schedule a meeting. If a frequent user declined to enroll, we asked an open-ended question on the reason for declining. With the participants' permission, a CM team member contacted their primary care physician (PCP), if present, to inform him/her about the study and gather information.

Randomization was computer-generated and concealed from patients. ${ }^{19}$ The research nurse, CM team, ED staff and data collection manager were not blinded to participant allocation, due to their activities and contacts. We informed study participants that they might receive CM services, without informing them of their group allocation. The statistician was blinded until the analyses were completed.

The CM team administered the intervention for 6 months following enrollment (until January 2014); patients were followed during the 6-month intervention and for an additional 6 months, for a total of 12 months (through July 2014). 


\section{CM intervention and control groups}

In addition to standard emergency care, participants in the intervention group received the $\mathrm{CM}$ intervention at baseline and at 1, 3, and 5 months (Online Appendix 1). The baseline visit lasted $1.5 \mathrm{~h}$, and follow-up visits took 30-60 min. An interdisciplinary mobile team consisting of four nurse practitioners and a chief resident ${ }^{23}$ provided the intervention in an ambulatory care, hospital, or home setting. With our "open-door policy," participants were given the telephone number and address of the $\mathrm{CM}$ team and could make contact between scheduled appointments.

The $\mathrm{CM}$ team provided individualized services to each participant in the intervention group, emphasizing care coordination and facilitating communication between health care team members. Specifically, CM team members provided counseling, based on motivational interviewing and crosscultural competences, on substance abuse (if applicable) and use of medical services. After assessing individual participant needs, we offered assistance to obtain income entitlements, improved housing (e.g. homeless shelters or asylum seeker housing), health insurance, domestic violence support and educational opportunities, to address these social determinants of health (SDH). Referrals were made to mental health services, substance abuse treatment or a new PCP on a case-bycase basis. As part of the CM intervention, we created a comprehensive care plan (Online Appendix 2) with practical recommendations for all of the participants' health care providers (PCP, psychiatrist, etc.). A key element of the intervention was establishing a link between providers and services at the hospital and community levels, promoting care continuity and improved orientation in the health care system.

Control group participants received only standard emergency care, but also met with a researcher during the 12 month follow-up (at 2, 5.5, 9 and 12 months), completing questionnaires related to outcomes which are not the focus of this paper (e.g. quality of life and the perception of discrimination ${ }^{24}$ ). Control group participants also received the CM team contact information, and anyone who contacted the team was eligible to receive $\mathrm{CM}$ services after the study.

\section{Study Data and Outcome Measures}

The primary outcome (number of ED visits) was obtained via the Lausanne hospital/ambulatory electronic records system and hospital/ambulatory administrative databases for each participant during the 12 months prior to and 12 months following enrollment.

Using validated standardized scales at baseline, we collected data on patient sociodemographic characteristics, SDH (including Medical Outcomes Study [MOS] survey $^{25}$ and subjective social status ${ }^{26}$ ), somatic (Charlson comorbidity inde $\mathrm{x}^{27}$ ) and mental health factors (Patient Health Questionnaire $[\mathrm{PHQ}]^{28}$, Mini-International Neuropsychiatric Interview [M.I.N.I.] $^{29}$ ), at-risk behaviors (Alcohol, Smoking and
Substance Involvement Screening Test ASSIST] $^{30}$ ), and health care utilization. ${ }^{22}$

\section{Statistical Analysis}

Statistical analyses were performed using STATA software (version 14; StataCorp LP, College Station, TX, USA), with the significance level set at $p=0.05$. All analyses followed intention-to-treat standards. Descriptive statistics were computed using means and standard deviations for continuous variables, and absolute frequencies and percentages for categorical variables. We applied a generalized linear model for count data (negative binomial distribution) using the number of ED visits during the 12 months following enrollment as the dependent variable. We included an offset variable (corresponding to the logarithm of survival time) to account for participants who died during the study. First, we performed bivariate analyses to test the effect of the participant group (intervention or control), the number of visits at baseline (12 months before enrollment), age, gender, education, citizenship, French proficiency, PCP, somatic, mental and social determinants, and at-risk behaviors as independent variables on the use of ED services during the 12 month follow-up. Second, we ran a stepwise regression including all these independent variables in order to select the predictive variables $(p=0.10)$ to be included in the multivariate model. Ratio and $95 \%$ confidence intervals were computed to estimate the effect size.

\section{RESULTS}

Of the 1145 frequent ED users identified during the recruitment period, we could not approach 217 (Fig. 1) due to pragmatic constraints for the single research nurse recruiting during periods of heavy patient influx, and 231 did not meet eligibility criteria. We were unable to contact 171 (after initial contact in the ED, they did not respond to follow-up calls), and 276 refused to participate. Reasons for declining included no expected benefit, not being satisfied with the hospital, and recent participation in another study. Those who refused did not differ in sex or nationality, but were older than enrolled participants (52.3 vs. 48.6 years old, $p=0.03$ ). Overall, 250 $(47.5 \%)$ agreed to participate and were allocated to the intervention $(n=125)$ or control group $(n=125)$.

\section{Participant Characteristics (Table 1)}

The mean age of the participants was 48.5 years $( \pm 18.9)$, and $57.2 \%$ were men. The intervention group had significantly lower educational attainment than controls. Participants reported high levels of poor SDH, including inadequate housing, lack of employment, and problems with immigration status. The majority suffered from a chronic condition, medical co-morbidity or psychiatric illness, and a third reported at- 


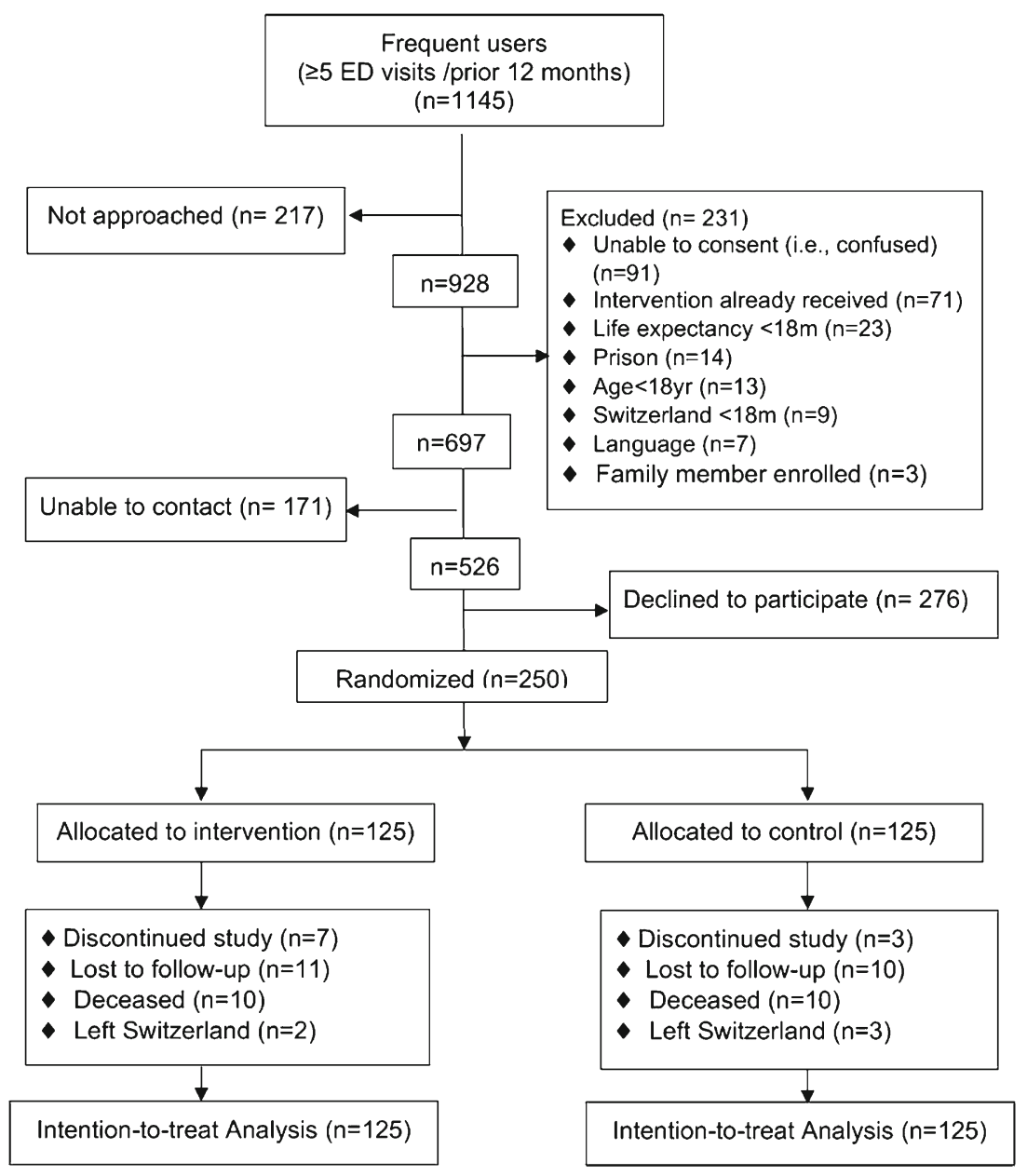

Figure 1 Enrollment flow chart.

risk behaviors. Only $14 \%$ did not have a PCP. The groups had an equal number of ED visits in the 12 months prior to enrollment.

\section{Study Implementation}

All 125 intervention group participants received the intervention at baseline, $106(84.8 \%)$ at 1 month, $98(78.4 \%)$ at 3 months, and $93(74.4 \%)$ at 5 months; $108(86.4 \%)$ intervention group participants contacted the CM team between study visits. No control group participants contacted the CM team proactively. Twenty participants (10 in each group) died during the study.

The CM team referred 66 participants $(52.8 \%)$ to mental health professionals and $34(27.2 \%)$ to substance abuse treatment. Sixty participants $(48.0 \%)$ received additional social services, and 83 $(66.4 \%)$ were referred to specialized medical doctors.

\section{Outcome (Table 2)}

During the 12 month follow-up, control group participants made an average of $3.35 \pm 0.32$ ED visits, whereas intervention group participants made $2.71 \pm 0.23$ visits, corresponding to $19 \%$ fewer ED visits (ratio $=0.81,95 \% \mathrm{CI}=0.63$ to 1.02 ).
The effect of the CM intervention (i.e. group) on the number of ED visits was not statistically significant in the bivariate model, $(b=-0.217, p=0.080)$ (Table 2). The association between social determinants and the number of visits approached statistical significance $(b=0.272, p=0.055)$, with poor SDH being associated with higher ED use, in the bivariate model. Group assignment (intervention or control) and social determinants were used in the stepwise multivariate regression. In this model, the effect of the group approached significance $(b=$ $-0.219, p=0.075)$, with the intervention group making fewer ED visits compared to the control group. The presence of poor SDH was significant in the final model $(b=0.280, p=0.048)$.

\section{DISCUSSION}

In this randomized controlled trial, a CM intervention led to $19 \%$ fewer ED visits by frequent users, which approached statistical significance, through an improved orientation to and coordination of services within the health care system. Our results also demonstrate that the presence of poor SDH-including social isolation, housing instability, or financial insecurity - was associated with higher ED use among frequent users. 
Table 1 Baseline Characteristics of the Study Population

\begin{tabular}{|c|c|c|c|}
\hline & $\begin{array}{l}\text { Total } \\
(n=250)\end{array}$ & $\begin{array}{l}\text { Intervention } \\
\text { group }(n=125)\end{array}$ & $\begin{array}{l}\text { Control group } \\
(n=125)\end{array}$ \\
\hline \multicolumn{4}{|l|}{ Sociodemographic characteristics $(\%, n)$} \\
\hline Male & $57.2(143)$ & $56.0(70)$ & $58.4(73)$ \\
\hline Age (mean, SD) & $48.5(18.9)$ & $48.4(18.7)$ & $48.6(19.1)$ \\
\hline \multicolumn{4}{|l|}{ Citizenship } \\
\hline Switzerland & $47.6(119)$ & $46.4(58)$ & $48.8(61)$ \\
\hline Europe & $17.6(44)$ & $19.2(24)$ & $16.0(20)$ \\
\hline Other (e.g. Africa, Asia, Lat Am) & $34.5(86)$ & $34.4(43)$ & $34.7(43)$ \\
\hline \multicolumn{4}{|l|}{ Education } \\
\hline High school/vocational school & $45.2(113)$ & $39.2(49)$ & $51.2(64)$ \\
\hline University/College & $16.8(42)$ & $13.6(17)$ & $20.0(25)$ \\
\hline Compulsory school only, do not know or other & $38.0(95)$ & $47.2(59)$ & $28.8(36)$ \\
\hline Uninsured & $2.8(7)$ & $2.4(3)$ & $3.2(3)$ \\
\hline Limited French proficiency & $18.8(47)$ & $18.4(23)$ & $19.2(24)$ \\
\hline No Primary care physician & $14.0(35)$ & $16.0(20)$ & $12.0(15)$ \\
\hline Number of ED visits (mean, SD) & $6.2(2.1)$ & $6.1(1.9)$ & $6.2(2.3)$ \\
\hline $5(\%, n)$ & $54.8(137)$ & $51.2(64)$ & $58.4(73)$ \\
\hline $6(\%, n)$ & $20.8(52)$ & $24.0(30)$ & $17.6(22)$ \\
\hline $7(\%, n)$ & $9.2(23)$ & $10.4(13)$ & $8.0(10)$ \\
\hline $8(\%, n)$ & $6.0(15)$ & $5.6(7)$ & $6.4(8)$ \\
\hline $9(\%, n)$ & $3.6(9)$ & $4.8(6)$ & $2.4(3)$ \\
\hline 10 or more $(10-24)(\%, n)$ & $5.6(14)$ & $4.0(5)$ & $7.2(9)$ \\
\hline Social determinants (any) $(\%, n)^{*}$ & $72.8(182)$ & $74.4(93)$ & $71.2(89)$ \\
\hline Complex family situation & $43.6(109)$ & $45.6(57)$ & $41.6(52)$ \\
\hline Social isolation & $31.2(78)$ & $30.4(38)$ & $32.0(40)$ \\
\hline Financial hardship & $49.6(124)$ & $50.4(63)$ & $48.8(61)$ \\
\hline Inadequate housing (homeless or refugee housing) & $24.0(60)$ & $26.4(33)$ & $21.6(27)$ \\
\hline Lack of employment or other activities & $50.4(126)$ & $54.4(68)$ & $46.4(58)$ \\
\hline Limited French proficiency & $16.0(40)$ & $12.8(16)$ & $19.2(24)$ \\
\hline Problem with immigration status & $22.0(55)$ & $24.0(30)$ & $20.0(25)$ \\
\hline Somatic determinants (any) $(\%, \mathrm{n}) \dagger$ & $69.2(173)$ & $69.6(87)$ & $68.8(86)$ \\
\hline Chronic and/or acute severe illness & $59.2(148)$ & $61.6(77)$ & $56.8(71)$ \\
\hline Comorbidity & $23.2(58)$ & $24.0(30)$ & $22.4(28)$ \\
\hline Polypharmacy & $17.2(43)$ & $20.0(25)$ & $14.4(18)$ \\
\hline Treatment non-adherence & $6.4(16)$ & $8.8(11)$ & $4.0(5)$ \\
\hline Mental determinants (any) $(\%, n)^{\ddagger}$ & $50.8(127)$ & $47.2(59)$ & $54.4(68)$ \\
\hline Depression & $27.2(68)$ & $23.2(29)$ & $31.2(39)$ \\
\hline Anxiety disorder & $31.6(79)$ & $28.8(36)$ & $34.4(43)$ \\
\hline Personality disorder & $6.0(15)$ & $4.8(6)$ & $7.2(9)$ \\
\hline Psychotic disorder & $3.2(8)$ & $2.4(3)$ & $4.0(5)$ \\
\hline At-risk behaviors (any) $(\%, n)^{\S}$ & $32.0(80)$ & $34.4(43)$ & $29.6(37)$ \\
\hline Alcohol use & $27.6(69)$ & $28.8(36)$ & $26.4(33)$ \\
\hline Tobacco use & $29.6(74)$ & $32.0(40)$ & $27.2(34)$ \\
\hline Illicit drug use & $10.8(27)$ & $11.2(14)$ & $10.4(13)$ \\
\hline
\end{tabular}

**MOS Social Support Survey ${ }^{25}$ and subjective social support survey ${ }^{26}$

${ }^{+}$Charlson score ${ }^{27}$

${ }^{7} \mathrm{PQ}^{28}$ and M.I.N.I. ${ }^{29}$

${ }^{{ }_{A S S I S T}}{ }^{30}$

While our main results do not achieve statistical significance, $19 \%$ fewer ED visits is clinically relevant, given the significant time and resources required to care for frequent $\mathrm{ED}$ users. ${ }^{31-33}$ For example, in the USA (21-28\% of 130 million total visits), a reduction of the magnitude found in our study would translate into 5.1-6.8 million avoided visits annually. ${ }^{15,34}$ The non-significant reduction in ED use found in this study underscores the mixed evidence in the literature. At least seven prior studies ${ }^{12,13,35-39}$ showed ED use reductions following a $\mathrm{CM}$ or similar intervention, while five studies $^{9,11,14,40,41}$ did not. In terms of study design, sample size and intervention (i.e. in-person $\mathrm{CM}$ intervention), our trial most closely matches that of Shumway, ${ }^{12}$ who found an additional reduction of one ED visit. A 1997 RCT did not find a reduction in number of ED visits following a CM-like intervention ${ }^{11}$; however, they defined frequent use as greater than 10 annual ED visits, and thus their results may be difficult to compare to our own. Two RCTs conducted in Sweden used a lower threshold to define ED frequent use ( $>3$ visits), and implemented interventions different from ours. ${ }^{13,14}$ Differences in the definition of frequent use and in intervention design and setting may have contributed to these varying results. Our results may have been influenced by the fact that despite our use of a validated definition, ${ }^{1}$ most participants had only 5-6 visits at enrollment, and CM may be of greater benefit for those with higher baseline ED use, given the increased vulnerability of this group. ${ }^{12,42}$ Furthermore, over one-third of participants were from Africa, Latin America or Asia, regions of origin common for asylum seekers, refugees or undocumented immigrants living in Switzerland. The limited primary care services in these regions ${ }^{43}$ may have led to increased ED use among these participants. Finally, significantly lower education among intervention group participants may have increased ED use in this group. ${ }^{44}$ 
Table 2 Bivariate and Multivariate Models Predicting Number of ED Visits at Follow-Up

\begin{tabular}{|c|c|c|c|c|}
\hline \multirow[t]{2}{*}{ Variables } & \multicolumn{2}{|c|}{ Bivariate models $^{a}$} & \multicolumn{2}{|c|}{ Multivariate final model ${ }^{a, b}$} \\
\hline & $b^{\mathbf{c}}$ & p value & $\boldsymbol{b}$ & p value \\
\hline Intervention group $^{d}$ & -0.217 & 0.080 & -0.219 & 0.075 \\
\hline Number of ED visits at enrollment (prior 12 months) & 0.026 & 0.333 & - & - \\
\hline Male $\mathrm{e}^{\mathrm{s}}$ & -0.119 & 0.342 & - & - \\
\hline Age & -0.003 & 0.416 & - & - \\
\hline \multicolumn{5}{|l|}{ Citizenship $^{\mathrm{f}}$} \\
\hline Europe & -0.063 & 0.717 & - & - \\
\hline Other (e.g. Africa, Asia, Lat Am) & -0.022 & 0.872 & - & - \\
\hline \multicolumn{5}{|l|}{ Education $^{\mathrm{g}}$} \\
\hline High school/vocational school & 0.080 & 0.606 & - & - \\
\hline University/college & -0.050 & 0.799 & - & - \\
\hline Do not know/other & 0.164 & 0.442 & - & - \\
\hline Limited French proficiency & -0.073 & 0.442 & - & - \\
\hline No primary care physician & -0.257 & 0.166 & - & - \\
\hline Social determinants ${ }^{\mathrm{h}}$ & 0.272 & 0.055 & 0.280 & 0.048 \\
\hline Somatic determinants ${ }^{\mathrm{i}}$ & 0.078 & 0.562 & - & - \\
\hline Mental determinants ${ }^{j}$ & 0.169 & 0.172 & - & - \\
\hline At-risk behaviors ${ }^{\mathrm{k}}$ & -0.003 & 0.980 & - & - \\
\hline
\end{tabular}

${ }^{a}$ Generalized linear model for count data (negative binomial distribution)

${ }^{b}$ Stepwise regression $(p=0.10)$

$c$ " $b$ " is the coefficient of the regression model

${ }^{d}$ Reference category: controls

${ }^{e}$ Reference category: female

${ }^{f}$ Reference category: Swiss nationality

${ }^{g}$ Reference category: compulsory school only

${ }^{h}$ Social determinants (at least one determinant): complex family situation, social isolation, financial hardship, inadequate housing, lack of employment, limited French proficiency, problems with immigration status

${ }^{i}$ Somatic determinants (at least one determinant): chronic and/or acute severe illness, comorbidity, polypharmacy, treatment non-adherence

${ }^{j}$ Mental determinants (at least one determinant): depression, anxiety, personality disorder, psychotic disorder

${ }^{k}$ At-risk behaviors (at least one determinant): alcohol use, tobacco use, Illicit drug use

Another important consideration is that the number of ED visits decreased in both groups. Contact between control group participants and the research team may have introduced contamination bias, contributing to a reduction in ED use among controls. However, despite receiving information about the CM team at enrollment, no control group participant proactively contacted the team to seek out services. A second explanation is that ED use becomes less frequent over time (i.e. regression to the mean), even without intervention. ${ }^{7,19}$ Finally, the Hawthorne effect - that people have a tendency to change their behavior when under observation - may have influenced ED use among these participants. In the Reinius study, ${ }^{13}$ control participants were passively observed in a Zelen's design, adopted in part to avoid a Hawthorne effect.

This pragmatic RCT has several limitations and strengths. First, we conducted this study at a single site, the sole tertiary care center in the canton of Vaud and one of five academic medical centers in Switzerland. However, in order to maximize the generalizability of our findings, we recruited a representative study sample of frequent ED users. ${ }^{16,45}$ In addition, the design of the Swiss health system - privatized but with universal coverage - allows for generalization of our findings to North America, Europe and parts of Asia. Second, the enrollment rate of $47.5 \%$ could have biased or contributed to our non-significant results. This suggests that $\mathrm{CM}$ services may not appeal to some frequent users, who may benefit from alternative outreach strategies. However, this enrollment rate is comparable to those of other studies, ${ }^{13}$ and we recruited an adequate number of participants based on power calculations. Although we anticipated a dropout rate of $30 \%$, we retained $78 \%$ of study participants. Our intention-to-treat analysis also reflects a "real world" scenario of caring for this highly vulnerable population. Third, we were unable to track the ED use of participants who visited an outside hospital or moved out of the area. Fourth, our small but experienced team was unable to approach 217 individuals during recruitment and were not blinded to allocation given their role in delivering the intervention; thus we cannot exclude a possible selection bias, despite specifically instructing our team against this. Fifth, excluding frequent users who had previously received CM services may have impacted our results. However, the characteristics of the frequent users we enrolled were qualitatively similar to participants in previous studies, ${ }^{16,22}$ suggesting that we recruited a representative sample. Finally, the 12-month study duration may have limited our ability to demonstrate the full scope of the benefit (or lack thereof) over a longer period. However, Shumway ${ }^{12}$ performed sensitivity analyses demonstrating similar cost-effectiveness of a CM intervention at 12 months and 24 months, suggesting that 1 year may be an appropriate study length.

Evidence regarding the impact of the $\mathrm{CM}$ on $\mathrm{ED}$ use remains inconclusive. A key goal of this $\mathrm{CM}$ intervention was to offer improved orientation and redirection to a range of hospital and community-based services. While most participants already had a PCP, caring for these highly vulnerable patients independently in the community is challenging. The 
main contribution of this intervention was to facilitate and coordinate care of frequent users, with the PCP integrated into this approach. The development of effective and efficient strategies to improve care for frequent users of the ED and other health services is an area of great interest. CM could serve as a link between disparate parts of complex health systems, with the PCP as the nexus for care continuity. CM teams should focus on modifiable $\mathrm{SDH}$ - such as housing or employment - in addition to traditional biomedical risk factors. Research investigating the impact of $\mathrm{CM}$ on specific highly vulnerable frequent users, such forced migrants or those with low health literacy, is warranted. Future research should explore patient-reported outcomes, and analyze costs at the institutional and community levels, taking into account the long-term needs of patients.

\section{Acknowledgments:}

This study was funded by the by the Swiss National Science Foundation (no: 32003B_135762).

The authors wish to thank the research team-Séverine Alary, Jolanta Nobs, and Sarah Kahnt-and the CM team (Corine Ansermet, Marina Canepa-Allen, and Laetitia LeNocher) for their contribution to the collection of the data and the medical care provided to the frequent users of the emergency department. We would also like to acknowledge Valentin Rousson for his invaluable guidance regarding our methodology and Phillipe Staeger for his clinical contributions to this study.

Prior Presentations:: Preliminary study findings were presented at the following:

- Society of General Internal Medicine (SGIM) 38th Annual Meeting, April 22-25, 2015, Toronto, ON, Canada, oral presentation (plenary session)

- Swiss Society of General Internal Medicine 83rd Annual Congress, May, 20-22, 2015, Basel, Switzerland (oral presentation, 2nd prize among oral presentations)

Corresponding Author: Patrick Bodenmann, MD, MSc; Vulnerable Populations Center, Department of Ambulatory Care and Community MedicineUniversity of Lausanne, Lausanne, Switzerland (e-mail: Patrick.Bodenmann@hospvd.ch).

\section{Compliance with Ethical Standards:}

Conflict of Interest: The authors declare that they do not have a conflict of interest.

\section{REFERENCES}

1. Locker TE, Baston S, Mason SM, Nicholl J. Defining frequent use of an urban emergency department. Emerg Med J. 2007;24(6):398-401.

2. van Tiel S, Rood PP, Bertoli-Avella AM, et al. Systematic review of frequent users of emergency departments in non-US hospitals: state of the art. Eur J Emerg Med. 2015.

3. Hoot NR, Aronsky D. Systematic review of emergency department crowding: causes, effects, and solutions. Ann Emerg Med. 2008;52(2): 126-136.e121.

4. Pines JM, Asplin BR, Kaji AH, et al. Frequent users of emergency department services: gaps in knowledge and a proposed research agenda. Acad Emerg Med. 2011;18(6):e64-e69.

5. Vu F, Daeppen J-B, Hugli O, et al. Screening of mental health and substance users in frequent users of a general Swiss emergency department. BMC Emerg Med. 2015;15(1):27.

6. Moe J, Kirkland S, Ospina MB, et al. Mortality, admission rates and outpatient use among frequent users of emergency departments: a systematic review. Emerg Med J. 2015. doi:10.1136/emermed-2014-204496.

7. Althaus F, Paroz S, Hugli O, et al. Effectiveness of interventions targeting frequent users of emergency departments: a systematic review. Ann Emerg Med. 2011;58(1):41-52.e42.
8. Kumar GS, Klein R. Effectiveness of case management strategies in reducing emergency department visits in frequent user patient populations: a systematic review. J Emerg Med. 2013;44(3):717-729.

9. Lee K-H, Davenport L. Can case management interventions reduce the number of emergency department visits by frequent users? Health Care Manag. 2006;25(2):155-159.

10. Case Management Society of America. What is a case manager? 2008-11; http://www.cmsa.org/Home/CMSA/WhatisaCaseManager/tabid/224/ Default.aspx. Accessed May 302016.

11. Spillane LL, Lumb EW, Cobaugh DJ, Wilcox SR, Clark JS, Schneider SM. Frequent users of the emergency department: can we intervene? Acad Emerg Med. 1997;4(6):574-580.

12. Shumway M, Boccellari A, O'Brien K, Okin RL. Cost-effectiveness of clinical case management for ED frequent users: results of a randomized trial`. Am J Emerg Med. 2008;26(2):155-164.

13. Reinius P, Johansson M, Fjellner A, Werr J, Öhlén G, Edgren G. A telephone-based case-management intervention reduces healthcare utilization for frequent emergency department visitors. Eur J Emerg Med. 2013;20(5):327-334.

14. Hansagi H, Olsson M, Hussain A, Öhlén G. Is information sharing between the emergency department and primary care useful to the care of frequent emergency department users? Eur J Emerg Med. 2008;15(1):34-39.

15. LaCalle E, Rabin E. Frequent users of emergency departments: the myths, the data, and the policy implications. Ann Emerg Med. 2010;56(1):42-48.

16. Bieler G, Paroz S, Faouzi M, et al. Social and medical vulnerability factors of emergency department frequent users in a universal health insurance system. Acad Emerg Med. 2012;19(1):63-68.

17. Organization for Economic Co-operation and Development (OECD). OECD Health Data: Social protection. 2013; http://www.oecd-ilibrary.org/socialissues-migration-health/data/oecd-health-statistics/oecd-health-data-social-protection_data-00544-en. Accessed May 30,2016.

18. Leu RE RF, Brouwer W, Matter P, Rütschi C. The swiss and dutch health insurance systems: Universal coverage and regulated competitive insurance markets. Website of the Commonwealth Fund: Commonwealth Fund 2009.

19. Bodenmann P, Velonaki V-S, Ruggeri O, et al. Case management for frequent users of the emergency department: study protocol of a randomised controlled trial. BMC Health Serv Res. 2014;14(1):264.

20. Sanchez B, Hirzel AH, Bingisser R, et al. State of emergency medicine in Switzerland: a national profile of emergency departments in 2006. Int $\mathrm{J}$ Emerg Med. 2013;6(1):1-11.

21. Rafnsson V, Gunnarsdottir OS. Mortality of the users of a hospital emergency department. Emerg Med J. 2006;23(4):269-273.

22. Bodenmann $\mathbf{P}$, Baggio S, Iglesias $\mathbf{K}$, et al. Characterizing the vulnerability of frequent emergency department users by applying a conceptual framework: a controlled, cross-sectional study. Int J Equity Health. 2015; 14(1): 146 .

23. Canepa Allen MCAC, Schüpbach J, Vu F, Bouche L, Ninane F, Bodenmann P. Respectful nursing support of patient priorities. Krankenpfl Soins Infirm. 2014;107(6):62-65.

24. Baggio S, Iglesias K, Hugli $\mathbf{O}$, et al. Associations between perceived discrimination and health status among frequent Emergency Department users. Eur J Emerg Med. 2015.

25. Sherbourne CD, Stewart AL. The MOS social support survey. Soc Sci Med. 1991;32(6):705-714.

26. Singh-Manoux A, Adler NE, Marmot MG. Subjective social status: its determinants and its association with measures of ill-health in the Whitehall II study. Soc Sci Med. 2003;56(6):1321-1333.

27. Charlson ME, Pompei P, Ales KL, MacKenzie CR. A new method of classifying prognostic comorbidity in longitudinal studies: development and validation. J Chronic Dis. 1987;40(5):373-383.

28. Spitzer RL, Kroenke K, Williams JB, PHQPCS Group. Validation and utility of a self-report version of PRIME-MD: the PHQ primary care study. JAMA. 1999;282(18): 1737-1744.

29. Sheehan DV, Lecrubier Y, Sheehan KH, et al. The Mini-International Neuropsychiatric Interview (MINI): the development and validation of a structured diagnostic psychiatric interview for DSM-IV and ICD-10. J Clin Psychiatry. 1998;59:22-33.

30. World Health Organization ASSIST Working Group. The alcohol, smoking and substance involvement screening test (ASSIST): development, reliability and feasibility. Addiction. 2002;97(9):1183-1194.

31. Moore G, Gerdtz M, Manias E, Hepworth G, Dent A. Socio-demographic and clinical characteristics of re-presentation to an Australian inner-city emergency department: implications for service delivery. BMC Public Health. 2007;7(1):320. 
32. Fuda KK, Immekus R. Frequent users of Massachusetts emergency departments: a statewide analysis. Ann Emerg Med. 2006;48(1):16. e1116. e18.

33. Dent AW, Phillips GA, Chenhall AJ, McGregor LR. The heaviest repeat users of an inner city emergency department are not general practice patients. Emerg Med. 2003;15(4):322-329.

34. National Hospital Ambulatory Medical Care Survey: 2011 Emergency Department Summary Tables. CDC;2011.

35. Wassmer R, Winward L, Derlet $\mathbf{R}$. Does counseling reduce frequent emergency department use? 2008.

36. Okin R, Boccellari A, Azocar F, et al. The effects of clinical case management on hospital service use among ED frequent users. Am J Emerg Med. 2000;18(5):603-608.

37. Pope D, Fernandes C, Bouthillette F, Etherington J. Frequent users of the emergency department: a program to improve care and reduce visits. CMAJ. 2000;162(7): 1017-1020.

38. Grover CA, Close RJH, Villarreal K, Goldman LM. Emergency department frequent user: pilot study of intensive case management to reduce visits and computed tomography. West J Emerg Med. 2010;11(4):336-343.
39. Skinner J, Carter L, Haxton C. Case management of patients who frequently present to a Scottish emergency department. Emerg Med J. 2009;26(2):103-105.

40. Wexler R, Hefner JL, Sieck C, et al. Connecting emergency department patients to primary care. J Am Board Fam Med. 2015;28(6):722-732.

41. Phillips G, Brophy D, Weiland T, Chenhall A, Dent A. The effect of multidisciplinary case management on selected outcomes for frequent attenders at an emergency department. Med J Aust. 2006;184(12):602-606.

42. Doupe MB, Palatnick W, Day S, et al. Frequent users of emergency departments: developing standard definitions and defining prominent risk factors. Ann Emerg Med. 2012;60(1):24-32.

43. World Health Organization. The World Health Report 2008: primary health care (now more than ever). 2014.

44. Berkman ND, Sheridan SL, Donahue KE, Halpern DJ, Crotty K. Low health literacy and health outcomes: an updated systematic review. Ann Intern Med. 2011;155(2):97-107.

45. Althaus F, Stucki S, Guyot S, et al. Characteristics of highly frequent users of a Swiss academic emergency department: a retrospective consecutive case series. Eur J Emerg Med. 2013;20(6):413-419. 